
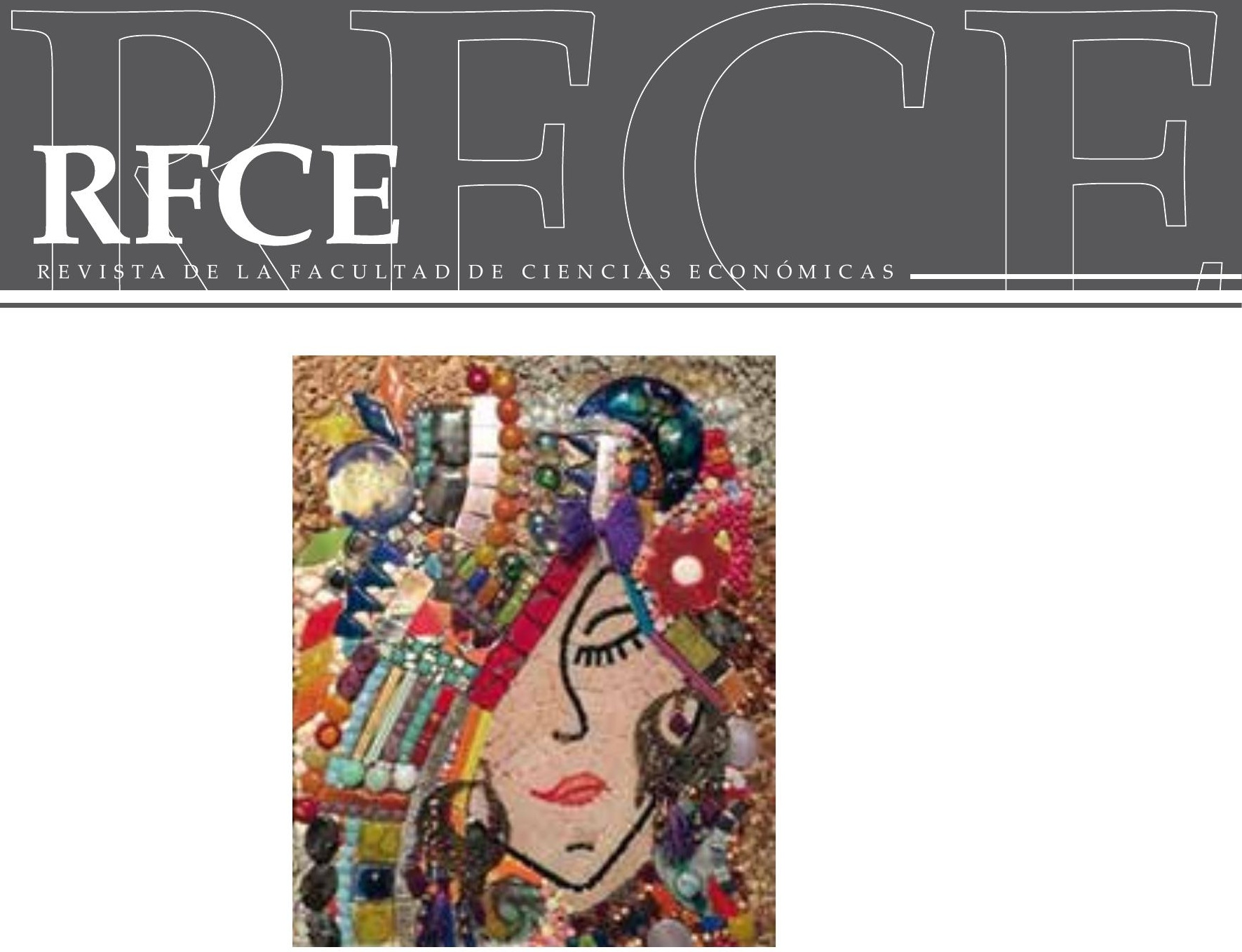

"LA SOÑADORA" Zully Ameri - 2017

\title{
PALABRAS PRELIMINARES
}

$\mathrm{C}$

on mucho gusto y satisfacción ponemos a consideración el número 17 de nuestra revista, correspondiente a la Primavera de 2016. Época de renacer, con energías de crecimiento y avance; especial para la acción creativa, la expansión y para compartir buenos momentos. Consideramos que el enfoque interdisciplinario de nuestra línea editorial resulta, actualmente, el medio eficiente y adecuado para la construcción y comunicación del conocimiento, en forma integrada, que siempre enriquece las visiones sobre diversos temas.

Los artículos que presentamos son atinentes a las áreas de Economía, Ciencia y Técnica, Derecho, Educación Superior y Relaciones Internacionales; de los cuales haremos un breve resumen, para dar una idea del contenido general.

En nuestra sección de arte, que estimamos contribuye a la concepción holística de la publicación, hemos elegido una disciplina que, a pesar de su larga historia, tiene en la actualidad un renacer importante: el mosaiquismo. Hemos invitado a Sandra Rodríguez Blanco directora del Taller Tesela Pink Chaco, de la ciudad de Resistencia, quien junto con sus alumnas, ofrecieran el material que nos ilustra. 
En la Sección de Artículos Científicos, el Profesor Hernán Alonso Bafico, perteneciente a la Universidad Nacional de La Plata, en Argentina y a la University of Denver, en EEUU, presenta un trabajo acerca de "Términos, cláusulas y condiciones para la incorporación de capital de riesgo", en el que caracteriza y analiza las cuestiones que normalmente debe negociar el emprendedor, para obtener financiamiento mediante la incorporación de inversores de capital de riesgo; realizando un estudio para un adecuado panorama de cuestiones estratégicas, financieras y económicas que el emprendedor debe conocer bien al evaluar las posibilidades de expansión de su negocio mediante la incorporación de inversores en títulos híbridos y de capital. En segundo término, el Licenciado Lucas Ariel Oviedo, de la Facultad de Ciencias Económicas de la Universidad Nacional del Nordeste analiza "Las políticas públicas de formación doctoral y su impacto en el Sistema Nacional de Ciencia, Tecnología e Innovación. Una lectura comparativa de Argentina y Brasil”, en el cual plantea una aproximación a comprender el impacto que, en términos de resultados de productos científicos y tecnológicos, han tenido las políticas públicas de formación doctoral implementadas en la última década en Argentina y Brasil. El estudio se complementa con una mirada estructural del Sistema de Ciencia y Tecnología latinoamericano, el cual presenta un conjunto de rasgos que condicionan las posibilidades de cambios sistémicos de este tipo de políticas públicas.

Seguidamente, al Abogado Especialista Mauricio Goldfarb, de la Facultad de Derecho y Ciencias Sociales y Políticas de la Universidad Nacional del Nordeste, aborda el tema de la "Intervención administrativa de los entes descentralizados en la Provincia de Corrientes, Argentina”, en el cual expone que la intervención administrativa de dichos entes es una forma de control excepcional sobre las entidades separadas de la administración central, que está regulada constitucional y legalmente como un modo de reestablecer su normal funcionamiento. Expone el marco normativo de la intervención y lo contrasta con la práctica y desarrollo de esta institución en la provincia de Corrientes, en los últimos 25 años.

A continuación, la Abogada Ingrid Rosas Villarrubia, de la Universidad Nacional del Nordeste, expone acerca del tema "Contratación electrónica y relación de consumo. Regulación en el Código Civil y Comercial de la República Argentina”. En el artículo trata acerca de la contratación electrónica dentro del régimen legal argentino, luego de la reforma y unificación del código civil y comercial. Presenta un análisis general del marco internacional, a su vez las conceptualizaciones para precisar el objeto de estudio y la referencia al mismo para, finalmente, hacer un análisis de lo introducido por la reforma de nuestro código vigente.

En quinto lugar, la Abogada Sandra Natalia Umansky, Becaria de la Secretaría General de Ciencia y Técnica de la Universidad Nacional del Nordeste, que cumple sus tareas en nuestra Facultad, presenta un estudio acerca de las "Funciones de la Responsabilidad Civil: cambio de paradigmas 


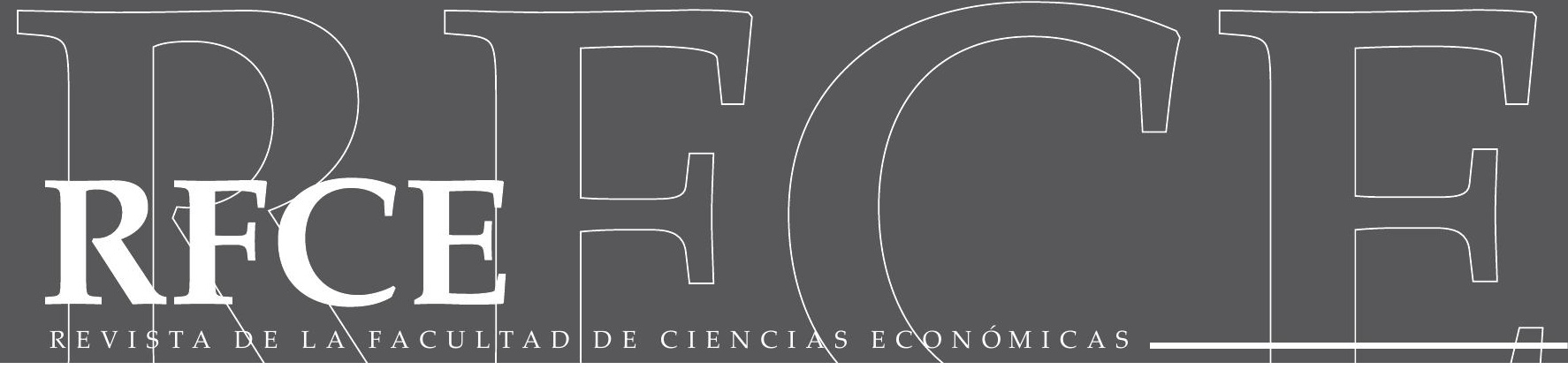

en el sistema de Derecho Privado argentino" que tiene por finalidad comentar la transformación operada en el sistema del Derecho Privado patrimonial argentino, a través de la inclusión de una variedad de funciones de la responsabilidad civil, arribando a interesantes conclusiones sobre la pluralidad actual de funciones; centralmente preventiva y resarcitoria; y periféricamente precautoria y punitiva, sosteniendo que el intérprete deberá realizar un adecuado diálogo de fuentes para la articulación del sistema, a fin de mantener la plena vigencia de esta polifuncionalidad.

Siguiendo el orden, el Dr. Jorge Gustavo Dahlgren, de la Facultad de Ciencias Económicas de la Universidad Nacional del Nordeste, presenta una colaboración sobre "La Justicia Laboral en la Provincia del Chaco. Innovaciones en el Procedimiento", en la cual brinda un panorama del estado actual del procesal laboral en dicho ámbito, luego de la reforma habida, con la inclusión de la instrumentación de la "audiencia de trámite", herramienta típica que caracteriza al procedimiento mixto; importante modificación al proceso laboral, en base al obligatorio contacto personal y directo de las partes y el juez, con la finalidad de dar celeridad al proceso. En el siguiente orden, los Profesores Rocco Antonio Rangel Rosso Nelson, del Instituto Federal do Rio Grande do Norte - IFRN, de Campus João Câmara e Isabel Cristina Amaral de Sousa Rosso Nelson, de la Universidade Estadual do Rio Grande do Norte - UERN, de Campus Mossoró, ambos de Brasil, realizan un análisis de "La regla constitucional de acumulación de cargos de Profesor en el ordenamiento jurídico brasilero - Da regra constitucional da acumulação de cargos de profesor no ordenamento jurídico brasileiro"; en el cual, partiendo de la norma de la Constitución brasileña de 1988, estudian el tema de la acumulación de cargos públicos y sus incompatibilidades, especialmente en lo atinente al profesional de la educación, al profesor y su especial problemática.

En el Sector de Comunicaciones, los Profesores Guido Zack, Federico Favata y Florencia Fares, pertenecientes a la Escuela de Economía y Negocios de la Universidad Nacional de San Martín, abordan el tema "Pobreza cero: la metodología de las promesas rotas", en el cual se detallan todas las modificaciones realizadas por el Instituto Nacional de Estadísticas y Censos (INDEC), en su actualización metodológica, mostrando su impacto marginal y total en las tasas y en las brechas de pobreza e indigencia. Asimismo, a partir de los datos del segundo trimestre de 2016, se evalúan las combinaciones de crecimiento y mejora en la distribución del ingreso necesarias para la eliminación de la pobreza y/o la indigencia para finales de 2019 y 2023.

Por su parte, los Profesores Gustavo Alejandro Girado, de la Universidad Nacional de La Matanza, Argentina y Daniel Kuschinski Kathmann, de la Universidad de Illinois, EEUU, realizan un interesante análisis acerca de "China y su política de internacionalización. El caso de las Zonas Económicas Exclusivas (ZEE) en África”, en el que exponen que China se ha convertido en una economía influyente a todo nivel, especialmente en lo que va del siglo 
XXI. Parte de su ascenso e impacto obedece a una serie de políticas vinculadas con la internacionalización de sus empresas (en el marco de una política mayor, “Go Global”), la que se desarrolla primero sobre su esfera de influencia regional, y luego en África, continente en donde sus inversiones pasan a tener gran relevancia. En su plan de relacionarse más estrechamente con economías con las cuales pretende mayores vínculos políticos y económicos, despliega su propia y exitosa experiencia de las ZEE en economías de mayor atraso relativo, con consecuencias divergentes hasta ahora.

Ponemos de manifiesto un agradecimiento sincero a quienes nos honran integrando el Comité Editorial y el Comité Científico, que hacemos extensivo a los autores y a las artistas, que han participado de este número y, por supuesto, a nuestros lectores, principales protagonistas de nuestra labor. Esta Comunidad de actores permite la subsistencia de esta publicación de carácter científico, con espíritu abierto para recibir aportes interesantes, caracterizada por el compromiso ético asumido.

El equipo que hace posible todas las tareas atinentes a la recepción, evaluación, edición y publicación de esta Revista es muy pequeño. Sin embargo, estamos consustanciados con la misión que tenemos entre manos: brindar a los autores la posibilidad de difundir su obra y a los lectores, nutrirse de ella. La tarea científica y académica nace para ser comunicada y transferida; esa es su razón de ser y éste pretende ser un humilde medio para contribuir con ello.

Agradezco muy especialmente a Silvina Andrea Cáncer, quien se desempeña como Secretaria y a Nicolás Gándara, que realiza los trabajos de diseño gráfico, mis pares en esta tarea; siempre dispuestos a aportar ideas, trabajo y, sobre todo, un profundo compromiso con el proyecto. iEs un placer integrar este grupo profesional, de alta calidad humana!

Respetando nuestra vocación integradora, no sólo entre disciplinas sino de la ciencia con el arte, hemos incluido imágenes y algunos pensamientos que invitan a la reflexión y, de ese modo, nos permiten conectar nuestro intelecto con la estética, con la emoción, con los sentimientos que, en su conjunto, conforman al ser humano.

$\mathrm{Al}$ presentar este ejemplar de la Revista, cumplimos otro ciclo y nos despedimos, en este formato, hasta el próximo Otoño de 2017. Mientras, mantendremos el contacto permanente mediante las redes sociales, agradeciendo los aportes que quieran hacernos para continuar creciendo, persiguiendo nuevas metas de excelencia.

\section{Cordialmente}

Dra. María Laura ESTIGARRIBIA BIEBER Directora

"Mirar es una cosa. Ver lo que se está mirando es otra. Entender lo que se ve, es aún otra. Llegar a aprender de lo que se entiende, es algo más. Pero llegar a actuar en base a lo que se ha aprendido, es todo lo que realmente importa."

Winston Churchill 